\title{
Calculation of Fusion Product Angular Correlation Coefficients for Fusion Plasmas
}

\author{
T. J. Murphy \\ Plasma Physics Laboratory, Princeton University \\ Princeton, New Jersey 08544
}

\begin{abstract}
The angular correlation coefficients for fusion products are calculated in the cases of Maxwellian and beam-target fusion plasmas. Measurement of these coefficients as a localized jon temperature or fast-ion diagnostic is discussed.
\end{abstract}

\section{DISCLAIMER}

This report was prepared as an account of work sponsored by an agency of the United States Government. Neither the United States Government nor any agency thereof, nor any of their employees, makes any warranty, express or implied, or assumes any legal liability or responsibility for the accuracy, completeness, or usefulness of any information, apparatus, preduct, or process disclosed, or represents that its use would not infringe privately owned rights. Reference hersin to any specific commercial product, process, or service by trade name, irademark, manufacturer, or ozherwise does not necessarily constitute or imply its endorsement, recommendation, or favoring by the United States Government or any agency thereof. The views and opinicns of authors expressed herein do not necessarily state or rellect those of the United Sta's Government or any agency thereor. 


\section{INTRODUCTION}

The measurement of fusion products in coincidence has been proposed $[1,2]$. These coincicience measurements would allow localized measurement of fusion product properiies, such as source strength and reactant velocity.

Calculations for that proposal took advantage of the fact that for reactions in fusion plasmas the energy released in the reaction $Q$ is much greater than the kinetic energy of the reacting particles. Because of this, the products of the reaction are born with velocities in nearly opposite directions. Thus, the velocity of the center of mass of the particles could be neglected compared to the velocity of the particles themselves.

In this paper, the effects of this center-of-rnass motion are investigated and the angular correlation coefficients for the products are calculated. That is, if the motion of one product defunes the $\theta=180^{\circ}$ direction, what is the probability distribution $f(\theta)$ of the direction of the second product's motion?

It is found that the width of the distribution is proportional to the square root of the temperature for Maxwellian plasmas. For beam-heated plasmas, the width of the beam-target correlation coefficient follows the same trend, but its maximum is displaced by an amount which is greatest for high beam energy and low larget temperature.

The magnitude of the deviation from $180^{\circ}$ is small, demonstrating that this deviation may in fact be neglected when calculating the coincidence efficiency of detector arrays[2]. It is, however, large enough to measure, especially in plasmas with a hot-ion component. The measurement of the deviation may thus be used to diagnose the velocity distribution of the hot ions.

\section{KINETICS}

The kinetics of the products of a fusion reaction of the form $a(b, c) d$ (Fig. 1) are completely determined by the total kinetic energy of the reacting particles, the center-of-mass velocity of the reaction, and the angle between the motion of either product and the direction of the center-of-mass velocity. In the center-

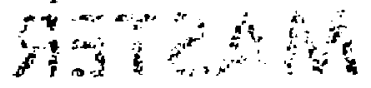


of-mass frame[3],

$$
\begin{aligned}
& E_{c}^{\prime}=\frac{m_{d}}{m_{c}+m_{d}}(K+Q), \\
& E_{c}^{\prime}=\frac{m_{c}}{m_{c}+m_{d}}(K+Q),
\end{aligned}
$$

and in the luboratory frame,

$$
\begin{aligned}
& E_{c}=\frac{m_{d}}{m_{c}+m_{d}}(K+Q)+\frac{1}{2} m_{c} V_{c m}^{2}+V_{c m} \cos \mu_{c} \sqrt{\frac{2 m_{c} m_{d}}{m_{c}+m_{d}}(K+Q)},(3) \\
& E_{d}=\frac{m_{c}}{m_{c}+m_{d}}(K+Q)+\frac{1}{2} m_{d} V_{c m}^{2}+V_{c m} \cos \mu_{d} \sqrt{\frac{2 m_{c} m_{d}}{m_{c}+m_{d}}(K+Q),(4)}
\end{aligned}
$$

where

$$
K=\frac{1}{2} \frac{m_{c} m_{b}}{m_{a}+m_{b}} v^{2},
$$

and $v$ is the magnitude of the relative velocity of the reacting particles. Using the law of cosines, the difference between $180^{\circ}$ and the angle formed by the fusion product velocities (Fig. 2) can be calculated in terms of the speeds of the particles in the laboratory and center-of-mass frames,

$$
\cos \theta_{c d}=1-\frac{\left(v_{c}+v_{d}\right)^{2}-\left(v_{c}^{\prime}+v_{d}^{\prime}\right)^{2}}{2 v_{c} v_{d}}
$$

In terms of the laboratory and center-of-mass energies,

$$
\cos \theta_{c d}=\sqrt{\frac{E_{c}^{\prime} E_{d}^{\prime}}{E_{c} E_{d}}}-\frac{\left(E_{c}-E_{c}^{\prime}\right) m_{d}+\left(E_{d}-E_{d}^{\prime}\right) m_{c}}{2 \sqrt{m_{c} m_{d} E_{c} E_{d}}} .
$$

If we define the parameters,

$$
\begin{aligned}
A & \equiv \frac{1}{2} V_{c m}^{2}, \\
B & \equiv V_{c m} \sqrt{2 m_{c} E_{c}^{\prime}}=V_{c m} \sqrt{2 m_{d} E_{d}^{\prime}} \\
\cos \mu & \equiv \cos \mu_{c}=-\cos \mu_{d},
\end{aligned}
$$

we can write,

$$
\begin{aligned}
& E_{c}=E_{c}^{\prime}+m_{c} A+B \cos \mu, \\
& E_{d}=E_{d}^{\prime}+m_{d} A-B \cos \mu .
\end{aligned}
$$


We may adopt the ordering:

$$
\epsilon \sim \sqrt{\frac{\frac{1}{2} m_{i} V_{c m}^{2}}{E_{i}^{\prime}}}
$$

for $i=c$ or $d . E_{i}$ is of the same order as $Q$, so for $V_{\mathrm{cm}}$ on the order of the thermal velocity, $\epsilon$ is on the order of 0.1 . Then,

$$
\begin{aligned}
\frac{B}{E_{i}^{\prime}} & \sim \epsilon, \\
\frac{m_{i} A}{E_{i}^{\prime}} & \sim \epsilon^{2} .
\end{aligned}
$$

We can solve for $\cos \theta_{c d}$ in terms of center-of-mass energies and $\cos \mu$ exactly,

$$
\begin{aligned}
\cos \theta_{c d}= & {\left[1-\frac{2 m_{c} m_{d} A+\left(m_{d}-m_{c}\right) B \cos \mu}{2 \sqrt{m_{\mathrm{c}} m_{d} E_{c}^{\prime} E_{d d}^{\prime}}}\right] } \\
& \times\left[\left(1+\frac{m_{c} A+B \cos \mu}{E_{c}^{\prime}}\right)\left(1+\frac{m_{d} A-B \cos \mu}{E_{d}^{\prime}}\right)\right]^{-\frac{1}{2}} .
\end{aligned}
$$

Solving this expression for $\cos \mu$, we find that the terms of order $\epsilon$ vanish. Therefore

$$
\cos ^{2} \mu=1-\frac{4 m_{c} m_{d}}{\left(m_{c}+m_{d}\right)^{3}} \frac{K+Q}{V_{c m}^{2}}\left(1-\cos \theta_{c d}\right),
$$

which is correct to order $\epsilon^{2}$. If we define $V_{\min }$ as the value of $V_{c m}$ for which $\cos ^{2} \mu=0$, we find that.

$$
V_{\min }=\sqrt{\frac{4 m_{c} m_{d}}{\left(m_{c}+m_{d}\right)^{3}}\left(1-\cos \theta_{c d}\right)(K+Q)}
$$

Then,

$$
\cos ^{2} \mu=1-\left(\frac{V_{\text {min }}}{V_{c m}}\right)^{2}
$$

\section{ANGULAR CORRELATION COEFFICIENTS}

The angular correlation coefficient is defined to be the probability that a product of a fusion reaction will leave the volume of jnterest at a certain angle relative to the other product of the reaction. This coefficiest may be written,

$$
f\left(\theta_{c d}\right)=R\left(\theta_{c d}\right) / R
$$


where $R\left(\theta_{c d}\right)$ is the rate of fusion reactions with products having a relative angle of $\theta_{c d}$ and $R$ is the total fusion reaction rate.

\subsection{Maxwellian Plasma}

Using a notation similar to that of Brysk $[3\}$, we can write an expression for the reaction rate for fusion reactions of given center-of-mass and relative velocities and given angle between velocities of the reacting ions:

$$
\begin{aligned}
& P\left(\mu^{\prime}, v, V_{1}, \mu, \phi\right) d\left(\cos \mu^{\prime}\right) d v d V d(\cos \mu) d \phi=n_{a} n_{b} \frac{1}{\pi}\left(\frac{m_{a} m_{b}}{T_{a} T_{b}}\right)^{3 / 2} \\
& \times \frac{\partial \sigma(v, \theta)}{\partial \Omega} v e^{-a V^{3}-\beta v^{2}-2 \gamma V v \cos \mu^{\prime}} d\left(\cos \mu^{\prime}\right) v^{2} d v V^{2} d V d(\cos \mu) d \phi,
\end{aligned}
$$

where

$$
\begin{aligned}
\alpha & \equiv \frac{1}{2}\left(\frac{m_{a}}{T_{a}}+\frac{m_{b}}{T_{b}}\right), \\
\beta & \equiv \frac{1}{2}\left(\frac{m_{b}}{T_{a}}+\frac{m_{a}}{T_{b}}\right) \frac{m_{a} m_{b}}{\left(m_{a}+m_{b}\right)^{2}}, \\
\gamma & \equiv \frac{1}{2}\left(\frac{1}{T_{a}}-\frac{1}{T_{b}}\right) \frac{2 m_{c} m_{b}}{m_{a}+m_{b}} \\
\cos \mu^{\prime} & \equiv \cos \mu_{a}=-\cos \mu_{b},
\end{aligned}
$$

and the reaction rate $R$ is given by

$$
R=\int_{-1}^{+1} d\left(\cos \mu^{\prime}\right) \int_{0}^{\infty} d v \int_{0}^{\infty} d V \int_{-1}^{+1} d(\cos \mu) \int_{0}^{2 \pi} d \phi P\left(\mu^{\prime}, v, V, \mu, \phi\right)
$$

We make the following substitutions to put the expression in terms we can use:

$$
\begin{aligned}
v^{2} & =2 \frac{m_{a}+m_{b}}{m_{a} m_{b}} K, \\
V & =V_{c m} .
\end{aligned}
$$

If we take $T_{a}=T_{b}=T$, then

$$
\begin{aligned}
\alpha & =\frac{m_{a}+m_{b}}{2 T} \\
\beta & =\frac{m_{a} m_{b}}{m_{a}+m_{b}} \frac{1}{2 T} \\
\gamma & =0
\end{aligned}
$$


In arder to make the substitution, we must first calculate the Jacobian for the transformation,

$$
\begin{aligned}
& J \equiv\left|\begin{array}{ccccc}
\frac{\theta \cos \mu^{\prime}}{\partial \cos \mu^{\prime}} & \frac{\theta \cos \mu^{\prime}}{\partial K} & \frac{\partial \cos \mu^{\prime}}{\partial V_{c m}} & \frac{\theta \cos \mu^{\prime}}{\partial \cos \theta_{c d}} & \frac{\partial \cos \mu^{\prime}}{\partial \phi} \\
\frac{\theta v}{\theta \cos \mu^{\prime}} & \frac{\partial V}{\partial K} & \frac{\theta v}{\partial V_{c m}} & \frac{\partial v}{\partial \cos \theta_{c d}} & \frac{\partial v}{\partial \phi} \\
\frac{\partial V}{\theta \cos \mu^{\prime}} & \frac{\partial V}{\partial K} & \frac{\theta V}{\partial V_{c m}} & \frac{\partial V}{\theta \cos \theta_{c d}} & \frac{\theta V}{\partial \phi} \\
\frac{\theta \cos \mu}{\partial \cos \mu^{\prime}} & \frac{\theta \cos \mu}{\partial K} & \frac{\theta \cos \mu}{\partial V_{c m}} & \frac{\theta \cos \mu}{\partial \cos \theta_{c d}} & \frac{\partial \cos \mu}{\theta \phi} \\
\frac{\theta \phi}{\theta \cos \mu^{\prime}} & \frac{\partial \phi}{\partial K} & \frac{\theta \phi}{\partial V_{c m}} & \frac{\theta \phi}{\theta \cos \theta_{c d}} & \frac{\partial \phi}{\partial \phi}
\end{array}\right| \\
& =\left|\begin{array}{ccccc}
I & 0 & 0 & 0 & 0 \\
0 & \frac{\partial v}{\partial K} & 0 & 0 & 0 \\
0 & 0 & 1 & 0 & 0 \\
0 & \frac{\theta \cos \mu}{\partial K} & \frac{\theta \cos \mu}{\partial V_{c-1}} & \frac{\theta \cos \mu}{\theta \cos \theta_{c d}} & 0 \\
0 & 0 & 0 & 0 & 1
\end{array}\right| \\
& =\frac{\partial v}{\partial K} \frac{\partial \cos \mu}{\partial \cos \theta_{e d}} \text {. }
\end{aligned}
$$

We can calculate this expression:

$$
\begin{aligned}
\frac{\partial \cos \mu}{\partial \cos \theta_{c d}} & = \pm\left\{2\left(1-\cos \theta_{c d}\right)\left(\frac{V_{c m}}{V_{\min }}\right) \sqrt{\left(\frac{V_{c m}}{V_{m i n}}\right)^{2}-1}\right\}^{-1} . \\
\frac{\partial v}{\partial K} & =\frac{1}{v} \frac{m_{a}+m_{b}}{m_{a} m_{b}} .
\end{aligned}
$$

The plus sign applies for $\cos \mu>0$ and the minus sign for $\cos \mu<0$.

From Brysk, we know that

$$
R=n_{a} n_{b}\left(\frac{m_{a}+m_{b}}{\pi m_{a} m_{b}}\right)^{1 / 2}\left(\frac{T}{2}\right)^{-3 / 2} \int_{0}^{\infty} d K K \sigma(K) \exp \left(-\frac{K}{T}\right)
$$

Since,

$$
\begin{aligned}
& P\left(\mu^{\prime}, v, V, \mu, \phi\right) d\left(\cos \mu^{\prime}\right) d v d V^{\prime} d(\cos \mu) d \phi \\
& \quad=P\left(\theta_{c d}, K, V_{c m}, \mu^{\prime}, \phi\right) J d\left(\cos \theta_{c d}\right) d K d V_{c m} d\left(\cos \mu^{\prime}\right) d \phi
\end{aligned}
$$

we can write

$$
\begin{aligned}
& R\left(\theta_{c d}\right) d\left(\cos \theta_{c d}\right) \\
& \quad=2 \int_{0}^{\infty} d K \int_{V_{\min }}^{\infty} d V_{c m}^{\prime} \int_{-1}^{+1} d\left(\cos \mu^{\prime}\right) \int_{0}^{2 \pi} d \phi P\left(\theta_{c d}, K, V_{c m}, \mu^{\prime}, \phi\right) J d\left(\cos \theta_{c d}\right)
\end{aligned}
$$


Since $0 \leq \cos ^{2} \mu \leq 1$ is satisfied by both $-1 \leq \cos \mu \leq 0$ and $0 \leq \cos \mu \leq 1$, the integral must be doubled, corresponding to integrating first from $V_{\mathrm{cm}} \rightarrow \infty$ to $V_{\mathrm{cm}}=V_{\mathrm{min}}$ using the minus sign in the Jacobian, and then form $V_{\mathrm{cm}}=V_{\min }$ to $V_{c m} \rightarrow \infty$ using the plus sign, and thus the factor of 2 in Eq. (29). By making the appropriate substitutions and simplifying, we find that

$$
f\left(\theta_{c d}\right)=\sqrt{\frac{1}{2 \pi}}\left(\frac{m_{a}+m_{b}}{T}\right)^{3 / 2} \times \frac{N}{D}
$$

where

$$
\begin{aligned}
N= & \frac{1}{1-\cos \theta_{c d}} \int_{0}^{\infty} d K K e^{-K / T} V_{\min }^{\mathrm{s}} \\
& \times \int_{1}^{\infty} d x \frac{x}{\sqrt{x^{2}-1}} e^{-\alpha V_{\min }^{2} z^{2}} \int_{-1}^{+1} d\left(\cos \mu^{\prime}\right) \int_{0}^{2 \pi} d \phi \frac{\partial \sigma}{\partial \Omega}(K, \theta), \\
D= & \int_{0}^{\infty} d K K \sigma(K) e^{-K / T},
\end{aligned}
$$

where $x \equiv V_{c m} / V_{\min }$. The integrals over $x, \cos \mu^{\prime}$ and $\phi$ simplify to leave

$$
f\left(\theta_{c d}\right)=\frac{m_{a}+m_{b}}{2 T} \times \frac{N^{\prime}}{D}
$$

where

$$
N^{\prime}=\frac{1}{1-\cos \theta_{r d}} \int_{0}^{\infty} d K K \sigma(K) V_{\min }^{2} e^{-K / T-\alpha V_{\min }^{2}}
$$

Equation (33) has been integrated numerically (Fig. 3) for the case of a D-T plasma using analytic fits to the cross section for the $\mathrm{d}(t, n) \alpha$ reaction quoted by Peres[4] below $1 \mathrm{MeV}$ and by Book[5] above $1 \mathrm{MeV}$. As expected, the distribution is peaked at $\theta_{c d}=0$ and has a width that increases with temperature, the half width at half maximum, $H W$ : of this distribution being approximately described by the formula

$$
H W=\sqrt{T / 4100 \mathrm{keV}}
$$

This behavior can be understood upon examination of Eq. (34). This integral contains the term $e^{-\alpha V_{\min }^{2}}$. $V_{\min }$ has only a weak dependence on $K$ in the region where the integrand is significant $(K \ll Q)$, so :t may be removed from the integra] after making the approximation,

$$
e^{-\alpha V_{m i n}^{2}} \approx \exp \left[-\frac{\theta_{c d}^{2}}{2} \frac{4 m_{c} m_{d}}{\left(\pi m_{c}+m_{d}\right)^{3}} \frac{m_{a}+m_{b}}{2 T} Q\right] .
$$


Thus,

$$
I W^{2} \approx T \frac{\left(m_{c}+m_{d}\right)^{2} \ln 2}{m_{c} m_{d} Q} .
$$

Table I lists the relationship between half width at half maximum and the temperature for reactions of interest.

\subsection{Anisotropic Plasma}

In the case of a bam-heated plasma, the majority of reactions can occur between fast beam particles and a Maxwellian target plasma. The beam-particle distribution will be anisotropir leading to a dependence of the angular correlation coefficient on the position of the detectors. The coefficient will also be a function of both polar angles, rather than being symmetric about the point opposite the primary detector as in the Maxwellian case.

The anisotropy of the beam distribution introduces the complication of $a$ preferred direction from which angles must be measured (Fig, 4). Thus, the direction to the primary detector can no longer be taken as the reference axis. In magnetized fusion plasmas, the direction of the magnetic field fixes the axis. The loss of flexibility in choosing an axis and the loss of the isotropy of the distribution cause the analytic calculation of the angular correlation coefficient for the general case to be much more difficult. These calculations can, however, be performed using a Monte-Carlo scheme:

1. Choose $\mathbf{v}_{b}$ and $\mathbf{v}_{t}$ from the desired distributions.

2. Calculate $\mathbf{V}_{c m}$ and $\mathbf{v}$.

3. Calculate $\cos \theta^{\prime}$ in the center-of-mass frame.

4. Calculate $\cos \theta_{d}$ and $\phi_{d}$.

5. Calculate $\frac{\partial o}{\partial n}$ in the lab frame.

6. Add the value $v \frac{\partial \sigma}{\partial \Omega}$ to the grid (centered on $\theta_{d}=\pi-\theta_{c}, \phi_{d}=\pi$ ).

7. Normalize so $\int_{-1}^{+1} d\left(\cos \theta_{d}\right) \int_{0}^{2 \pi} d \phi_{d} f\left(\theta_{d}, \phi_{d}\right)=1$. 
The velocities are chosen in the following manner. The beam distribution is taken to be a slowing down distribution, $f(v) \propto v^{-3}$. In order to choose velocities which follow this distribution for $v \in\left(v_{t h}, v_{\max }\right)$ using a random number $x$ from the interval $[0,1)$, we calculate

$$
v=v_{i h}\left(\frac{v_{\max }}{v_{t h}}\right)^{z},
$$

where

$$
\begin{aligned}
v_{\max }^{2} & =\frac{2 E_{b}}{m_{b}}, \\
v_{\neq h}^{2} & =\frac{2 T}{m_{t}} .
\end{aligned}
$$

The pitch angle is given and assumed constant for the distribution and the gyroangle is evenly distributed on the interval $[0,2 \pi)$.

The components of the target particie velocity are chosen by inverting the equation,

$$
2 x \dot{-1}=\frac{2}{\sqrt{\pi}} \int_{0}^{v_{\mathrm{m}} / v_{\mathrm{t} / h}} d t e^{-t^{2}}
$$

and similarly for $v_{y}$ and $v_{z}$. This equation may be solved numerically using the IMSL, Inc. routine[6] MERFI (inverse error function).

These velocities are split into Cartesian components, and $V_{c m}$ and $v$ are calculated from

$$
\begin{aligned}
\mathbf{v}_{c m} & =\frac{m_{b} v_{b}+m_{t} v_{t}}{m_{b}+m_{t}} \\
v & =v_{t}-v_{b}
\end{aligned}
$$

Since the direction to detector $C$ is fixed, the angle $\mu$ between the center-ofmass velocity $\mathrm{V}_{\mathrm{cm}}$ and the velocity of particle $C$, given by $\mathrm{v}_{\mathrm{c}}$, is known from

$$
\cos \mu=\frac{v_{c} \cdot V_{c m}}{v_{c} V_{c m}}
$$

Thus, the velocity of particle $C$ in the lab frame can be calculated using Eq. (3). The angle between the velocity of particle $C$ in the center-of-mass frame and the center-of-mass velocity can then be calculated from

$$
\cos \mu^{\prime}=\frac{\mathbf{v}_{c}^{\prime} \cdot V_{\mathrm{cm}}}{v_{c}^{\prime} V_{\mathrm{cm}}},
$$


where $v_{c}^{\prime}=v_{c}-V_{c m}$. The direction of particle $D$ in the center-of-rinass and lab frames can be calculated using the definition of the center-of-mass frame

$$
m_{d} \mathbf{v}_{d^{\prime}}^{\prime}=-m_{c} v_{c}^{\prime}
$$

and $\mathbf{v}_{d}=\mathbf{v}_{d}^{\prime}+\mathbf{V}_{\mathrm{c} \boldsymbol{m}}$.

The differential cross section $\partial \sigma / \partial \Omega$ is a function of the angle $\theta^{\prime}$ between the relative velocity $\mathbf{v}$ and $\mathbf{v}_{c}$. Since the direction of $\mathbf{v}_{c}$ is known and the direction of $v_{c}^{\prime}$ can be calculated, the differential cross section in the center-of-mass frame carı also be calculated. To transform from the center-of-mass frame to the lab frame, this number is multiplied by the Jacobian, defined by

$$
J \equiv \frac{\partial \cos \mu^{\prime}}{\partial \cos \mu}
$$

We can combine Egs. (44) and (45) to obtain

$$
\cos \mu^{\prime}=\frac{v_{c} \cos \mu-V_{c m}}{v_{c}^{\prime}} .
$$

From this, the Jacobian may be calculated,

$$
J=\frac{v_{\mathrm{c}}}{v_{\mathrm{c}}^{\prime}} \frac{1}{\left(1-\frac{\left.V_{c \mathrm{~m}} \cos \mu\right)}{v_{\mathrm{c}}}\right)}
$$

Thus, for each set of randomly chosen $v_{b}$ and $\boldsymbol{v}_{t}$, the rate of fusion reactions, $v \frac{\theta \sigma}{b \bar{R}}$, may be calculated, and the rate for particle $D$ moving in a certain direction may be calculated. By making calculations based on many thousands of such randomly chosen velocities, the angular correlation coefficient may be numerically de duced for arbitrary rezeting-particle distributiont.

Figure 5 displays the results of calculations for deuterium beam injection into a tritium plasma. The neutron is taken to be particle $C$, so the distribution is that of the a particle. The differential cross section of the $t(d, n j a$ reaction is isotropic| 7 ], so it is given by $\partial \sigma / \partial \Omega=\tau / 4 \pi$. The Monte-Carlo calculations are in agreemer: with the analytic calculations for the Maxwellian case, showing a width that is proportional to the square root of the temperatur :-

The beam-target cases demonstrate fairly predictable behavjor. For the case of paraliel injection, with detector $C$ measuring particles with velocities 
perpendicular to the magnetic rield, the distribution of particle $D$ is displaced in the direction of the uearn by au amount which increases with beam energy. The distribution becomes vider as tems erature increases, and the displacement decreases due to the increasing contributicn of reactions from the high-energy tail of the Maxwellian target plasma. These tail ions, with velocities opposing the beam velocities, react more readily due to the increased cross section at the higher relative velocity and are displaced less due to tne decreased velocity of the center of mass. Thus, as the temperature is increased, the angular distribution approaches that of the Maxielliar case.

At higher $t$ mperatures, the parallel injection case exhibits rather strange behavior: the distribution becomes somewhat crescent shaped. This occurs because particles with large velocities perpendicular to the b-in relocity have a higher relative velocity than particles which have low velocities. Thus, there are more particles with large displacements in both $\cos \theta_{d}$ and $\phi_{d}$ than just in $\cos \theta_{\mathrm{d}}$.

The perpendicular injection cases also exhibit displacement, but in the $\phi_{d}$ cirection. Since the beam particles are moving both parallel and perpendicular to the direction of detector $C$, the distribution is spread out over a region including bot! positive and negative displacement in $\phi_{d}$, as well as the region in between. Again, as the temperature increases, ihere are more fast target ions with velocities opposing the beam-ion velocities, and the distribution again approaches that for the Maxwellian case. Thus, the largest deviation from the Maxwellian case occurs for high beam energy and low target-temperature.

\section{MEASUREMENT OF THE ANGULAR CORRELATION COEFFICIENT}

In order to make use of these calculations, a practical method for measuring fusion product angular correlation coefficients must be developed. This requires a coincidence system involving detectors which can measure the angle at which the particle strikes the detector. This can be accomplished by using several detectors each collimated differently or by using a position-sensitive detector in 
one branch of the system. Figure 6 shows schematically a detector system which could be used to measure the correlation coefficient in a tokamak plasma. Shown are orbits for the 14.7-MeV proton and 3.7- $\mathrm{MeV} \alpha$ particle from the $d\left({ }^{3} \mathrm{He}, \mathrm{p}\right) \alpha$ reaction. If all the products of the reaction were born with velocities $180^{\circ}$ to each other and were monoenergetic, only one orbit pair could be detected by a given pair of detectors. By introducing finite temperature or beam energy, the region of sensitivity is spread out due to the spread in the correlation and the change in the Larmor radii due to Doppler shifts in the energies of the products. By measuring the position at which the $\alpha$ particle strikes the position-sensitive detector in coincidence with the detection of a proton at the other detector, the angular correlation coefficient can be measured. From this, the temperature or beam distribution at the point of intersection of the two orbits can be deduced. Profiles can be determined by using a group of detectors, perhaps with one detector common to al] coincidence pairs. Figure 7 shows such an array for measuring reaction products on the Texas Experimeatal Tokamak, TEXT[8], at $2.0 \mathrm{~T}$ with a proton detector common to all pairs. At lower toroidal fields, the products of the $d(d, p) t$ reaction can be measured on TEXT $(1.5 \mathrm{~T})$ and the Princeton Beta Experiment, PBX (0.9 T).

\section{CONCLUSIONS}

For temperatures possible in present-day fusion reactors, the angular correlation coefficients of the fusion products are highly dependent on the temperature of the plasma and the distribution function of the reaciing ions. Measuring the width of the angular correlation in fusion devices would be useful in determining the ion temperature profile or beam distribution or in establishing the extent to which the ion distribution varjes from a Maxwellian. In beam-heated plasmas, this could be used to separate beam-target reactions from reactions only involving the Maxwellian target plasma.

The disadvantages of the method are that both products of the reaction must be lost promptly to the vessel wall before executing a single gyroorbit. Drifting orbits will spread too quickly and any information from coincidence. 
measurements will quickly be lost. The method also suffers from low count rates since the requirement of two promptly-escaping particles generally implies a small machine. The count rates are aiso limited by the number of random coincidences that will tend to hide the true coincidence rate[2].

\section{ACKNOWLEDGMENT}

This work was supported by the United States Department of Energy under contract No. DE-AC02-76-CHO-3073. 


\section{References}

1] Thomas Elevant, Nucl. Instrum. Math. 141 (1977) 603.

[2] T. J. Murphy, W. W. Heidbrink, and J. D. Strachan, Rev. Sci. Instrum. 57 (1986) 1766.

[3] H. Brysk, Plasma Phys. 15 (1973) 611.

[4] Asher Peres, J. Appl. Phys. 50 (1979) 5569.

[5] David L. Book, NRL Plasma Formulary (Office of Naval Research, Washington, 1983).

[6] IMSL, The IMSL Library Edition 9 Reference Manual (International Mathematical and Statistical Libraries, Inc., Houston, 1981).

7. E. Bretscher and A. P. French, Phys. Rev. 75 (1949) 1154.

i8] K. W. Gentle, Nucl. Tech./Fusion 1 (1981) 479. 


\section{Table}

Table I. The relationship between the temperature and the half width at half maximurn of the angular correlation coefficjent for aifferent reactions in a Maxwellian plasma.

\begin{tabular}{ccc}
\hline Reaction & $\begin{array}{c}Q \\
\mathrm{keV}\end{array}$ & $\begin{array}{c}T / H W^{2} \\
\mathrm{keV}\end{array}$ \\
\hline $\mathrm{d}(\mathrm{d}, \mathrm{n})^{3} \mathrm{He}$ & 3269 & 886 \\
$\mathrm{~d}(\mathrm{~d}, \mathrm{p}) \mathrm{t}$ & 4033 & 1092 \\
$\mathrm{~d}(\mathrm{t}, \mathrm{n}) \alpha$ & 17590 & 4080 \\
$\mathrm{~d}\left({ }^{3} \mathrm{He}, \mathrm{p}\right) \alpha$ & 18354 & 4255 \\
\hline
\end{tabular}




\section{Figures}

Fig. 1. Diagram of the coordinates used for (a) the iaboratory frame and (b) the center-of-mass frame. Particles $A$ and $B$ travel in the $A-B$ plane, while particles $C$ and $D$ travel in the $C-D$ plane. The intersection of the planes is the direction of travel of the center-of-mass of the pair of particlea befor: and after the fusion reaction.

Fig. 2. Diagram illustrating the connection between the velocities in the two different frames and the correlation angle $\theta_{c d}$.

Fig. 3. Calculated angular correlation coefficients for D-T plasmas for six different temperatu:es.

Fig. 4. Diagram of the coordinates used in the case of beam-target reactions in (a) the laboratory frame and (b) the center-of-mass frame. The location of detector $C$ fixes the direction of $\mathbf{v}_{c}$ and defines the $\phi=0$ plane. $v_{c}$ lies in the $x-z$ plane, the other velocities do not necessarily lie on any certain plane defined by a pair of the coordinate axes.

Fig. 5. Angular correlation coefficients calculated using a "Monte-Carlo" scheme: (a) Maxwellian plasma, (b) and (c) beam-target plasma with the detector at $\cos \theta=0$ and $\phi=0$ for perpendicular injection, and (d) and (e) beam-target plasma with the same detector location but for parallel injection.

Fig. 6. Schematic diagram of a system with which the angular correlation coefficient could be measured. The angles at which the orbits meet are exaggerated in this diagran for clarity, as is the distance between points at which reactions could occur and be detected by the same two detectors. The dotted line is tangent to the proton orbit at the point where it intersects the or-particle orbit to show the initial direction of the o-particle velocity had the particles been born with $\cdots$ locities $180^{\circ}$ to each other.

Fig. 7. One possible array of detectors for measuring the beam or temperature profile on TEXT at a toroidal magnetic field of $2.0 \mathrm{~T}$ using the $\mathrm{d}\left({ }^{3} \mathrm{He}, \mathrm{p}\right) \alpha$ 
reaction. At lower toroidal fields, the products of the $d(d, p) t$ reaction could be measured with a similar system. 


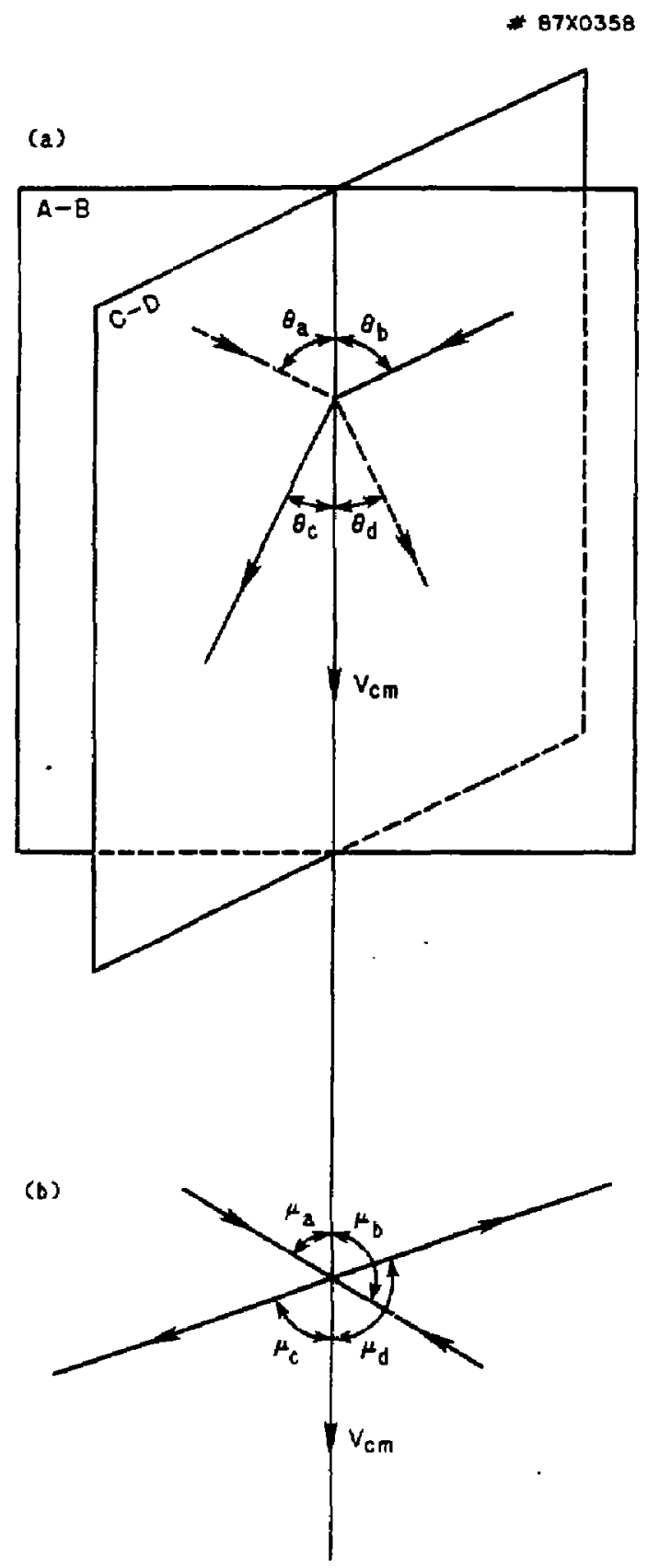

Fig. 1 


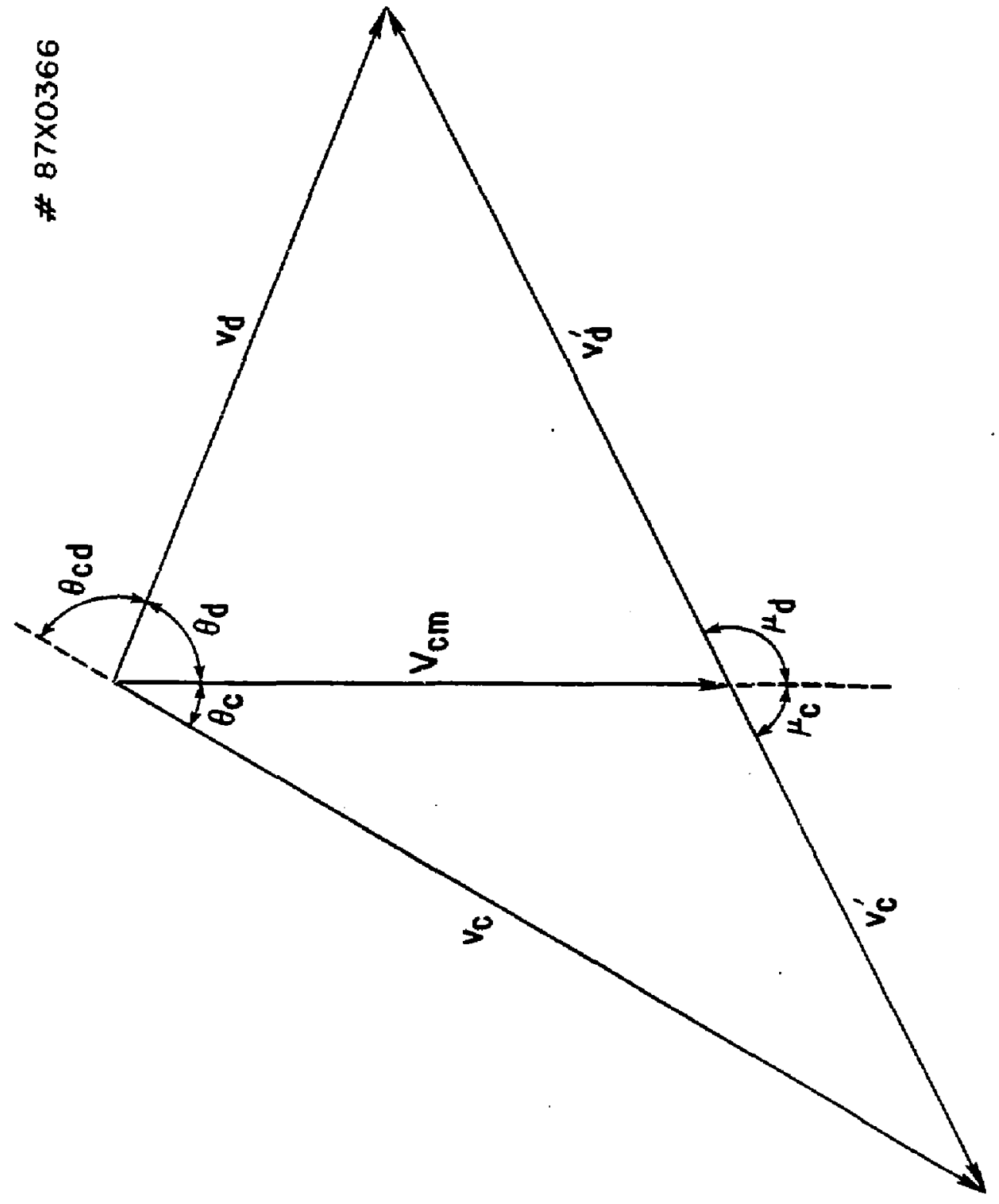



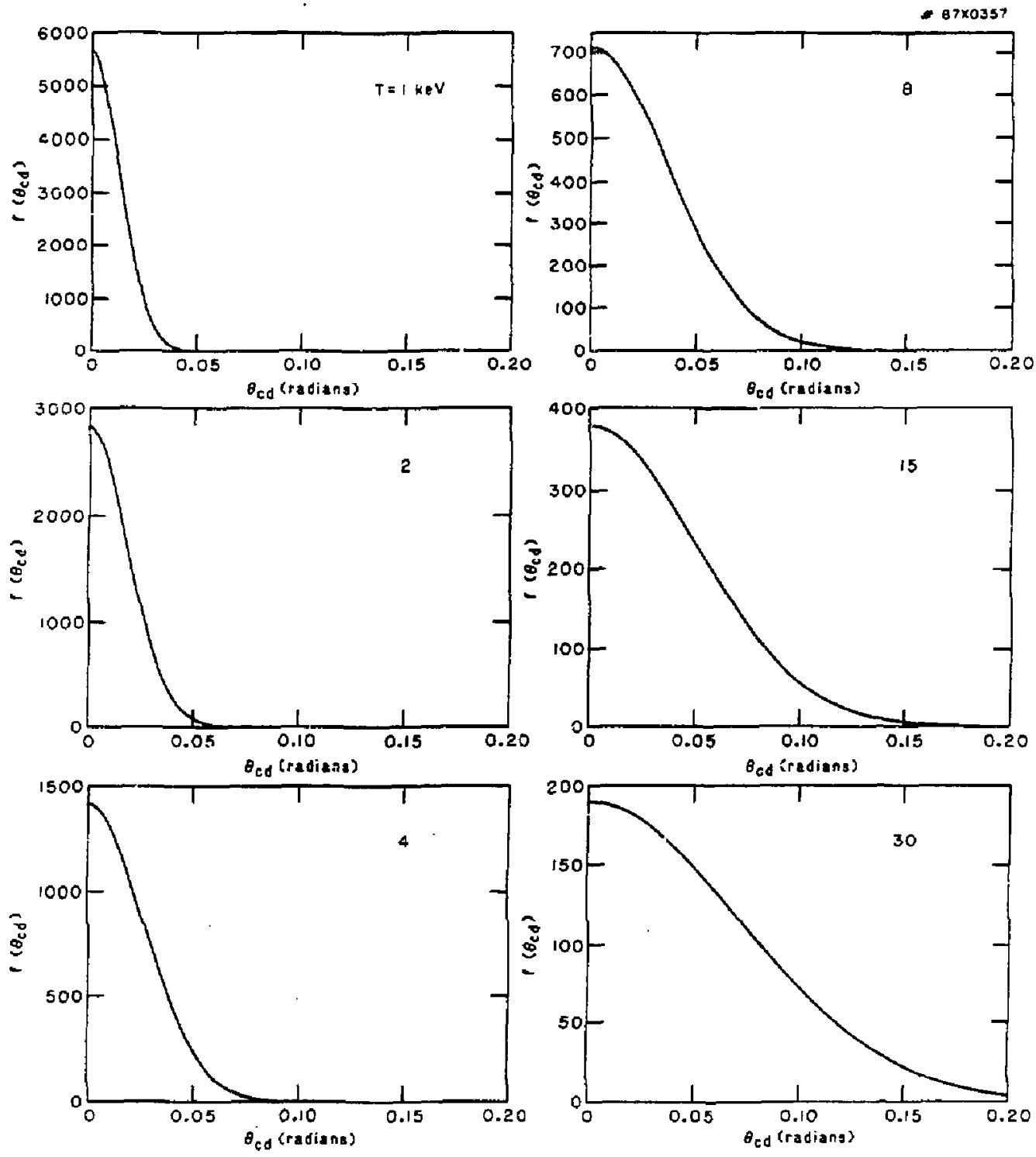

Fig. 3 

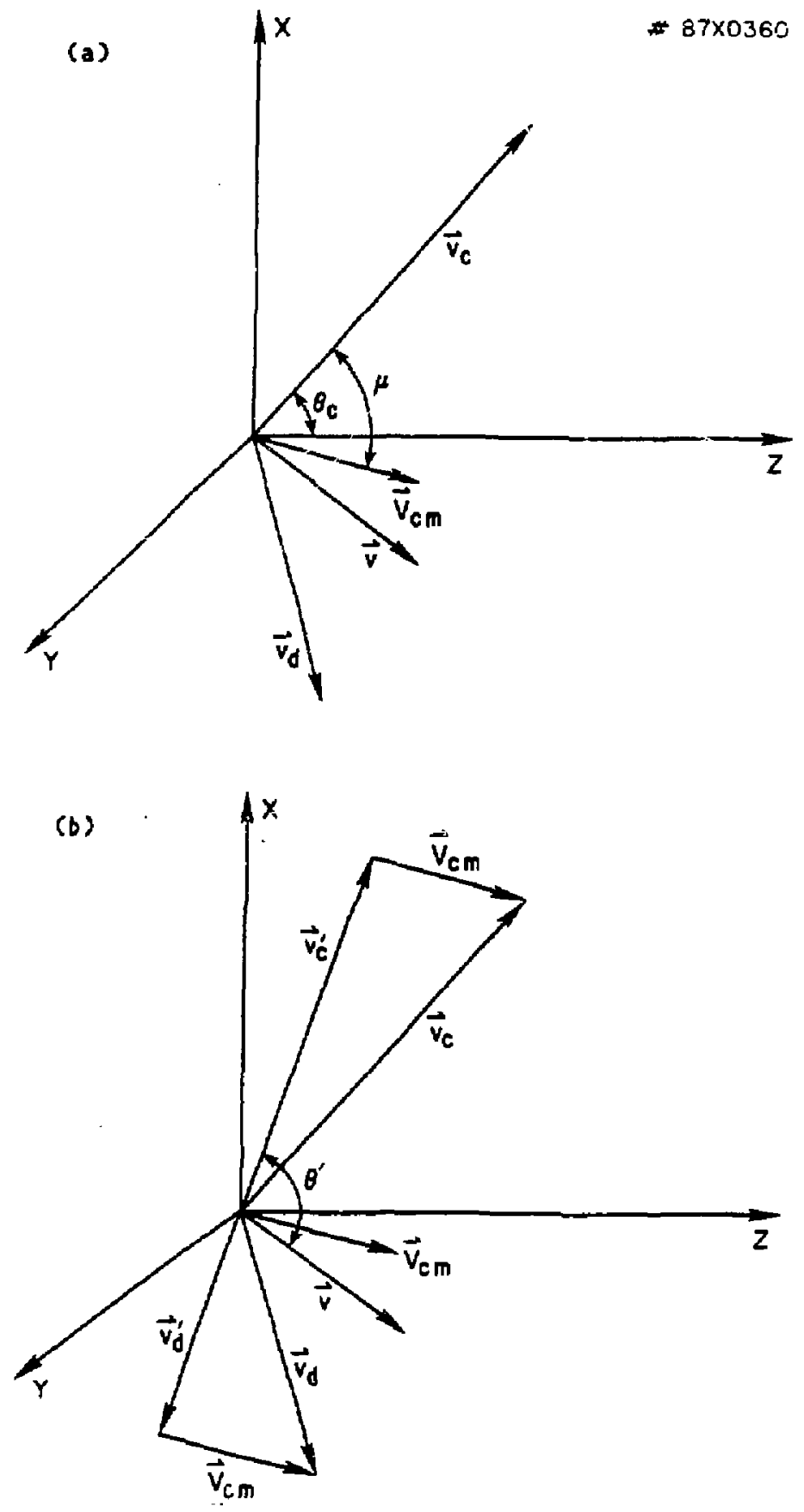

Fig. 4 

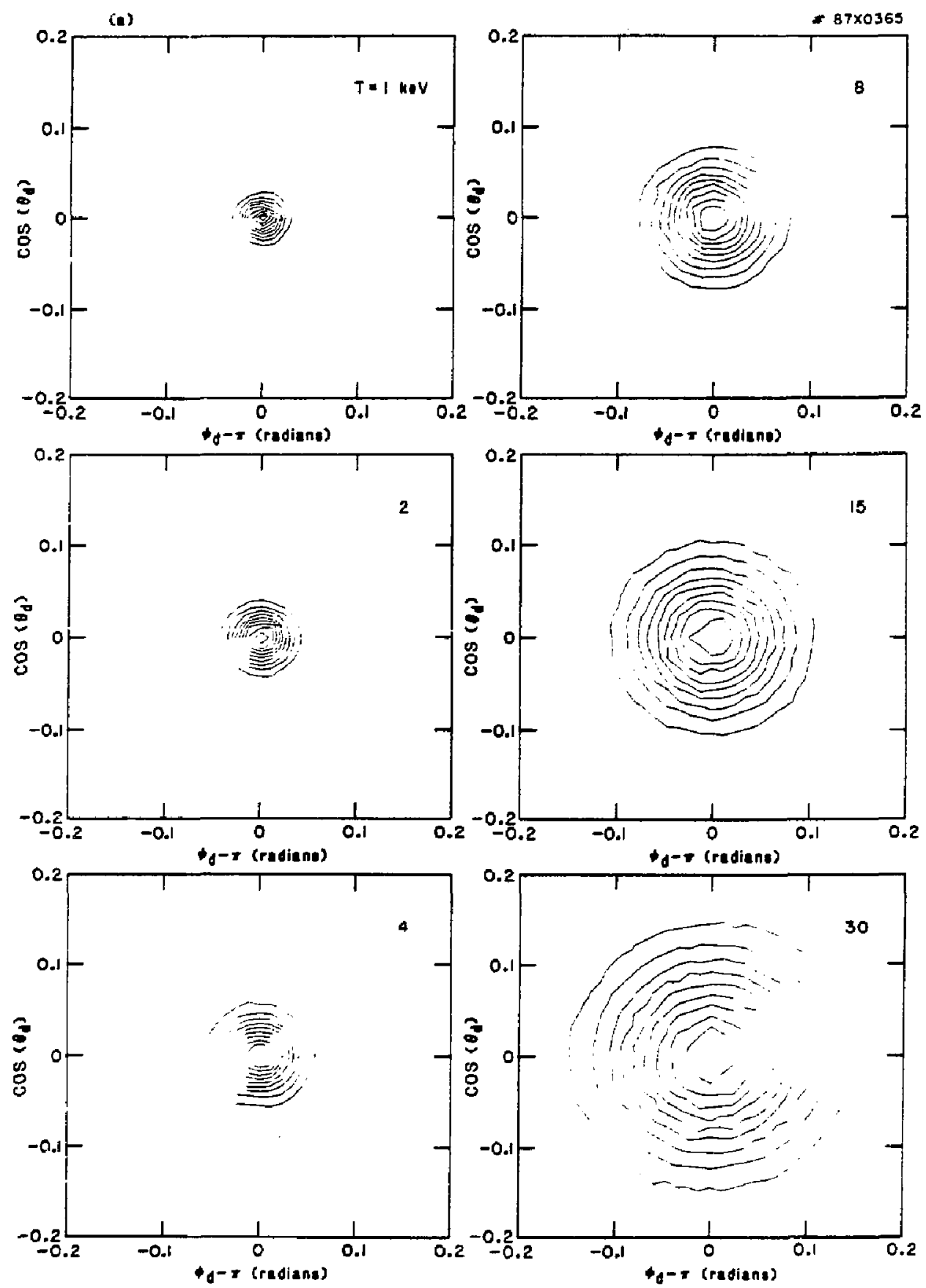

Fiq. $S(a)$ 

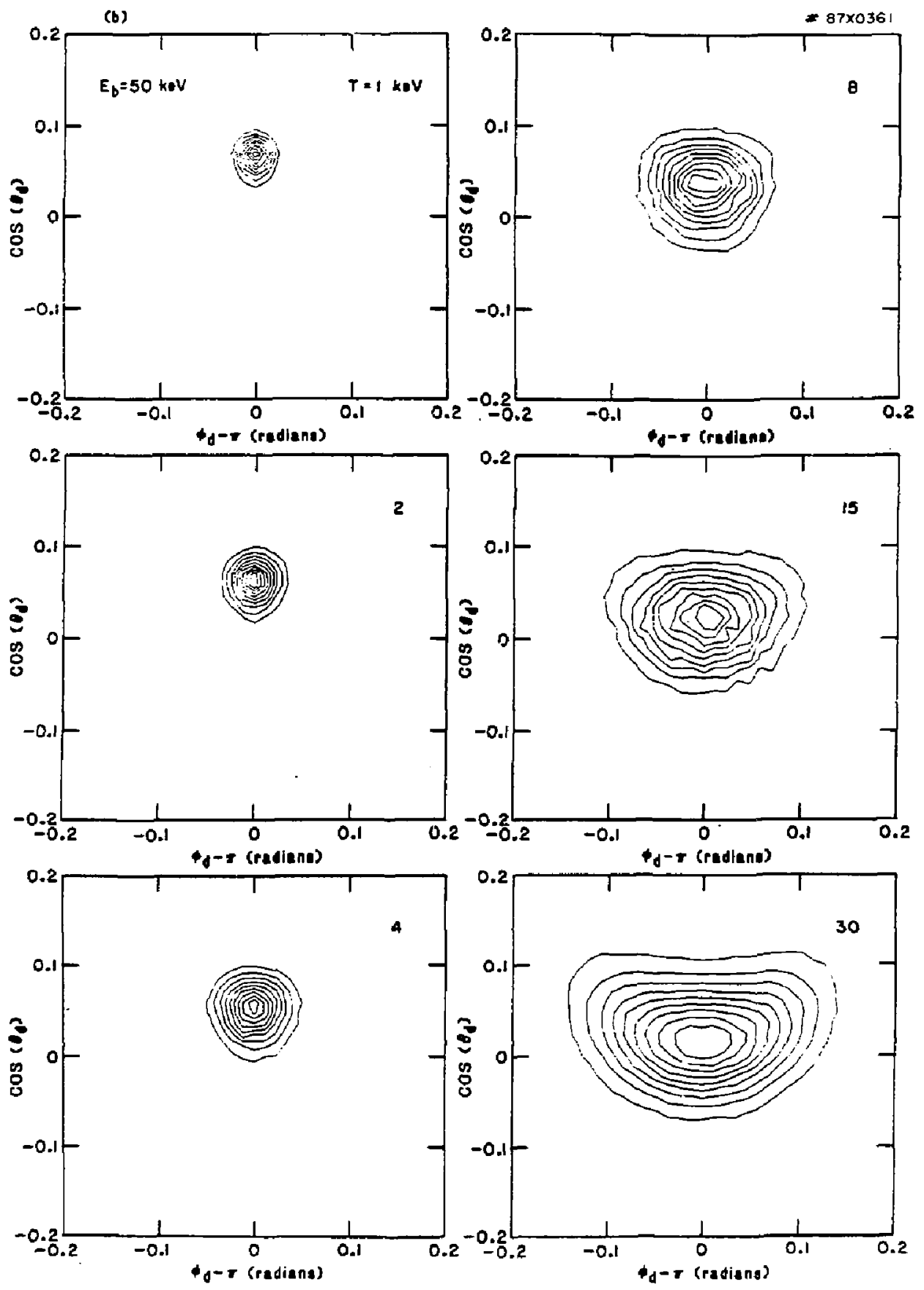

Fig. 5 (b) 

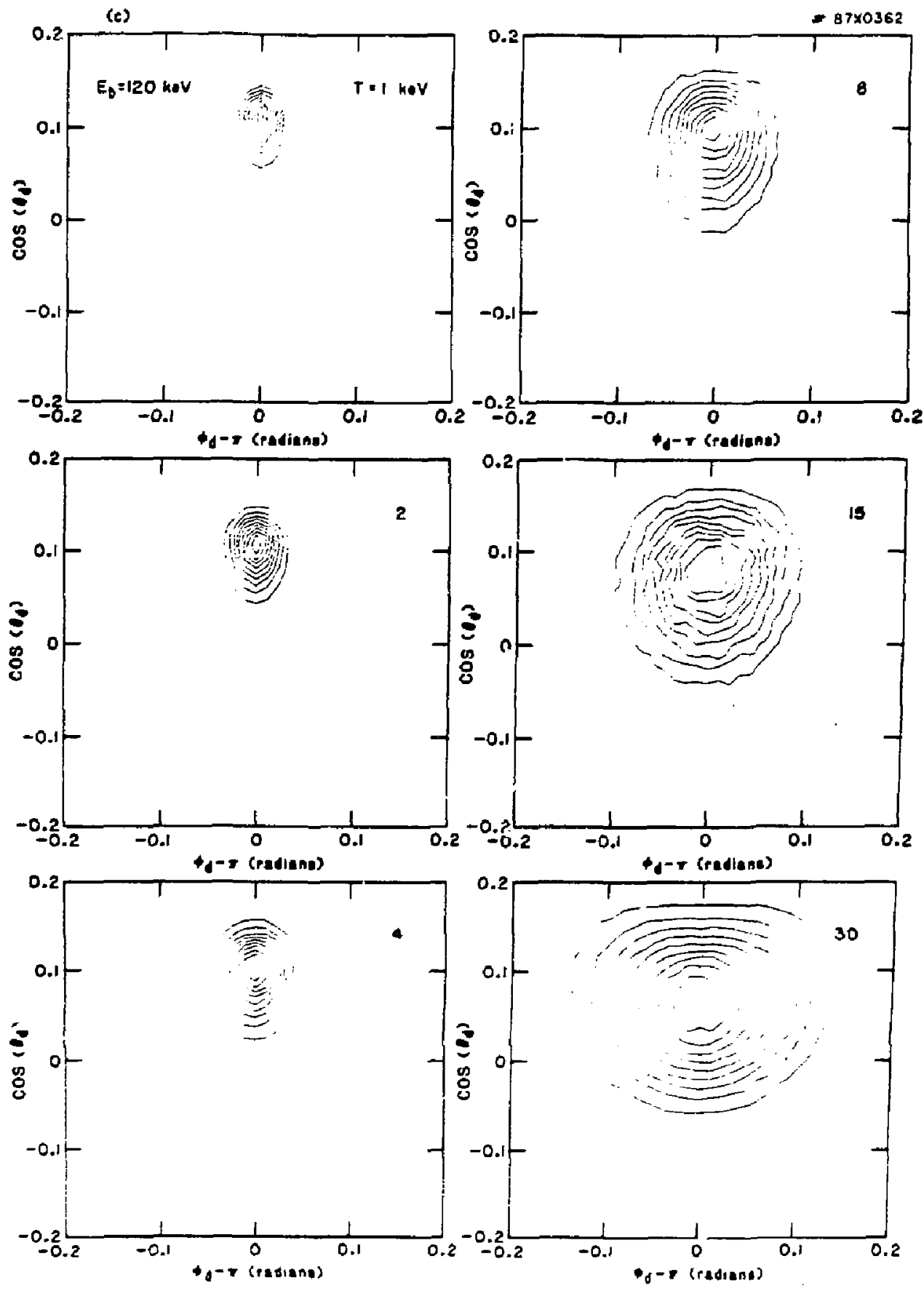

Fig. $5(\mathrm{c})$ 

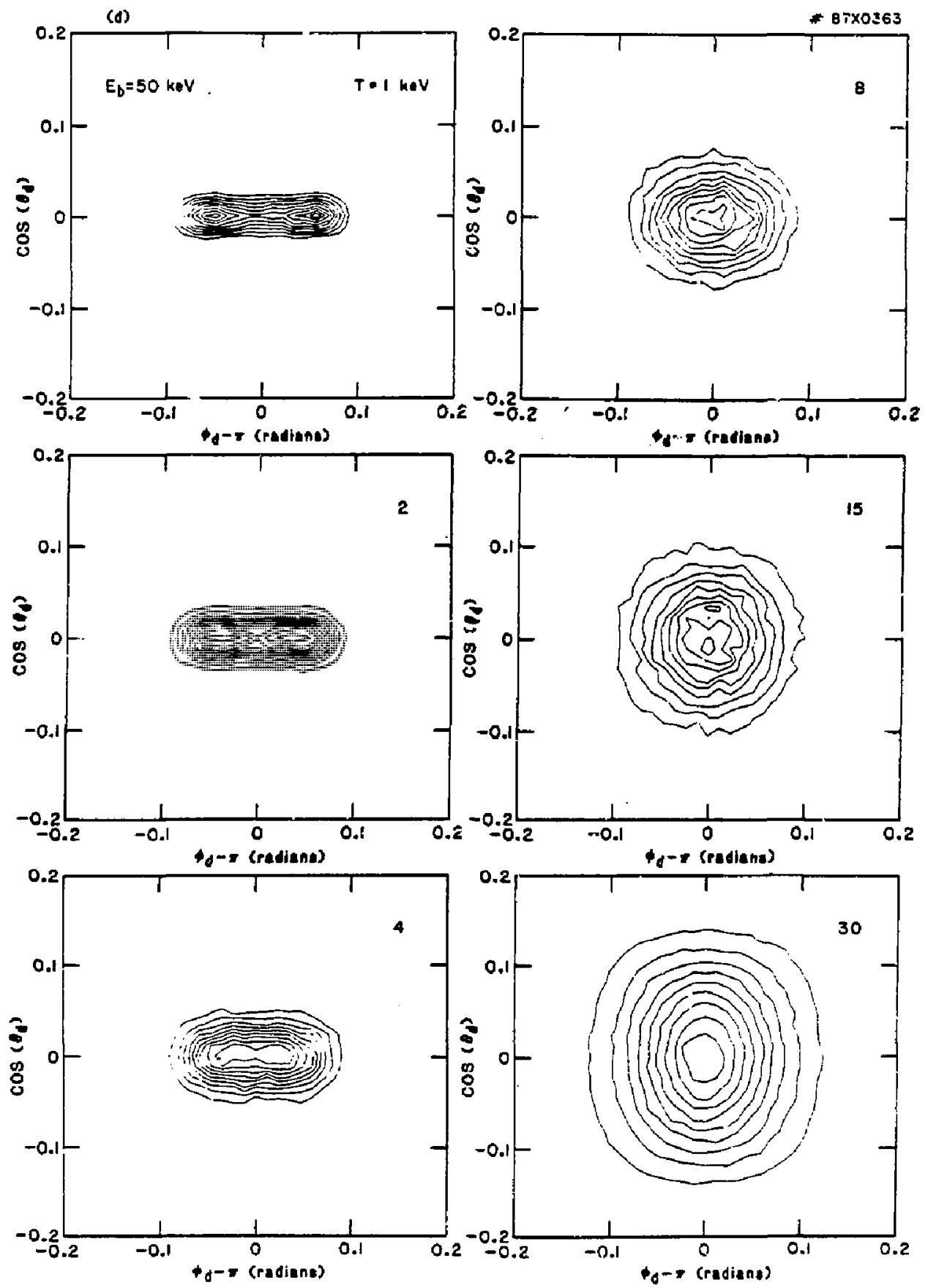

Fig. $5(d)$ 

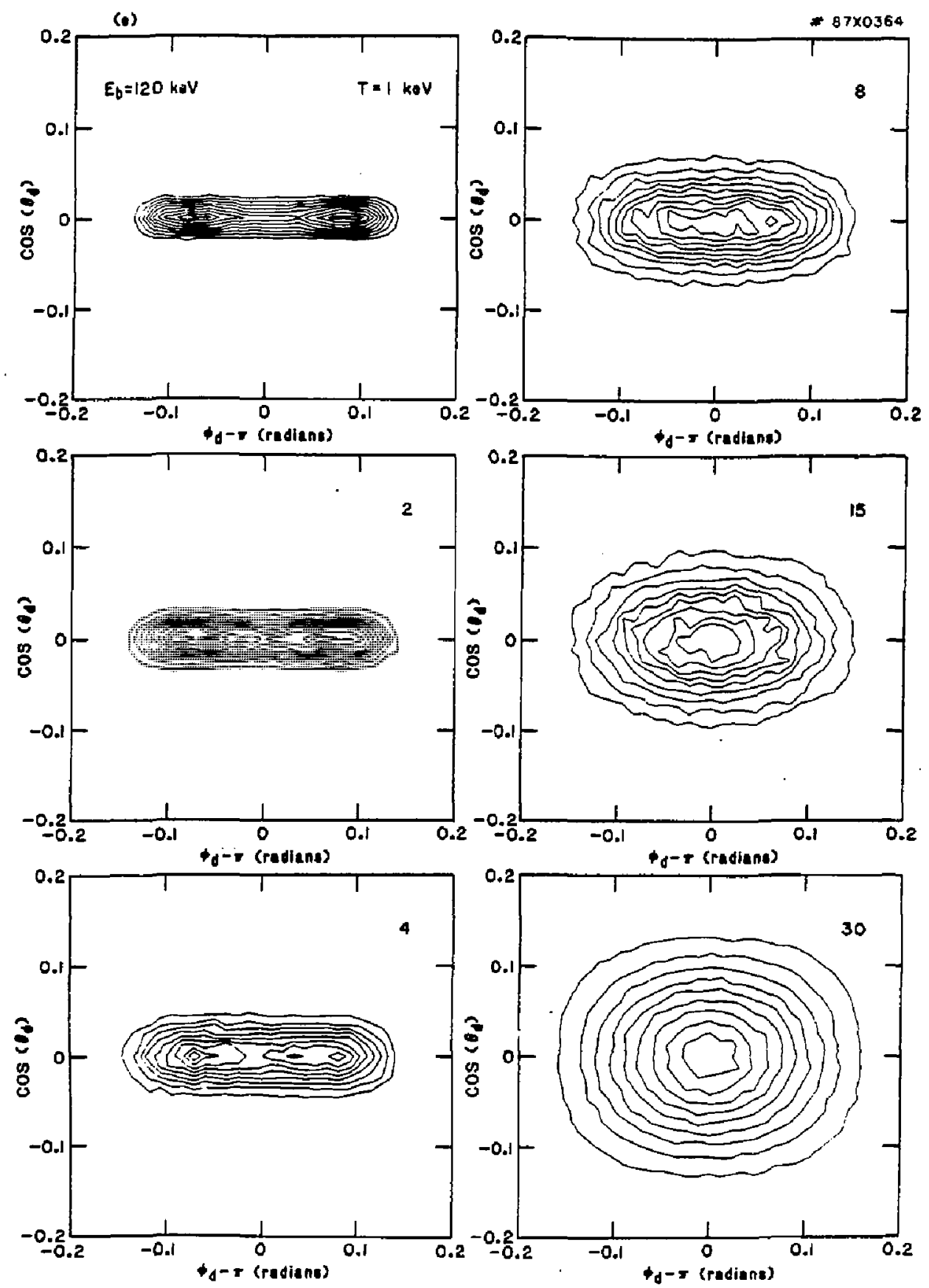

Fig. $5(e)$ 
\# $87 \times 0359$

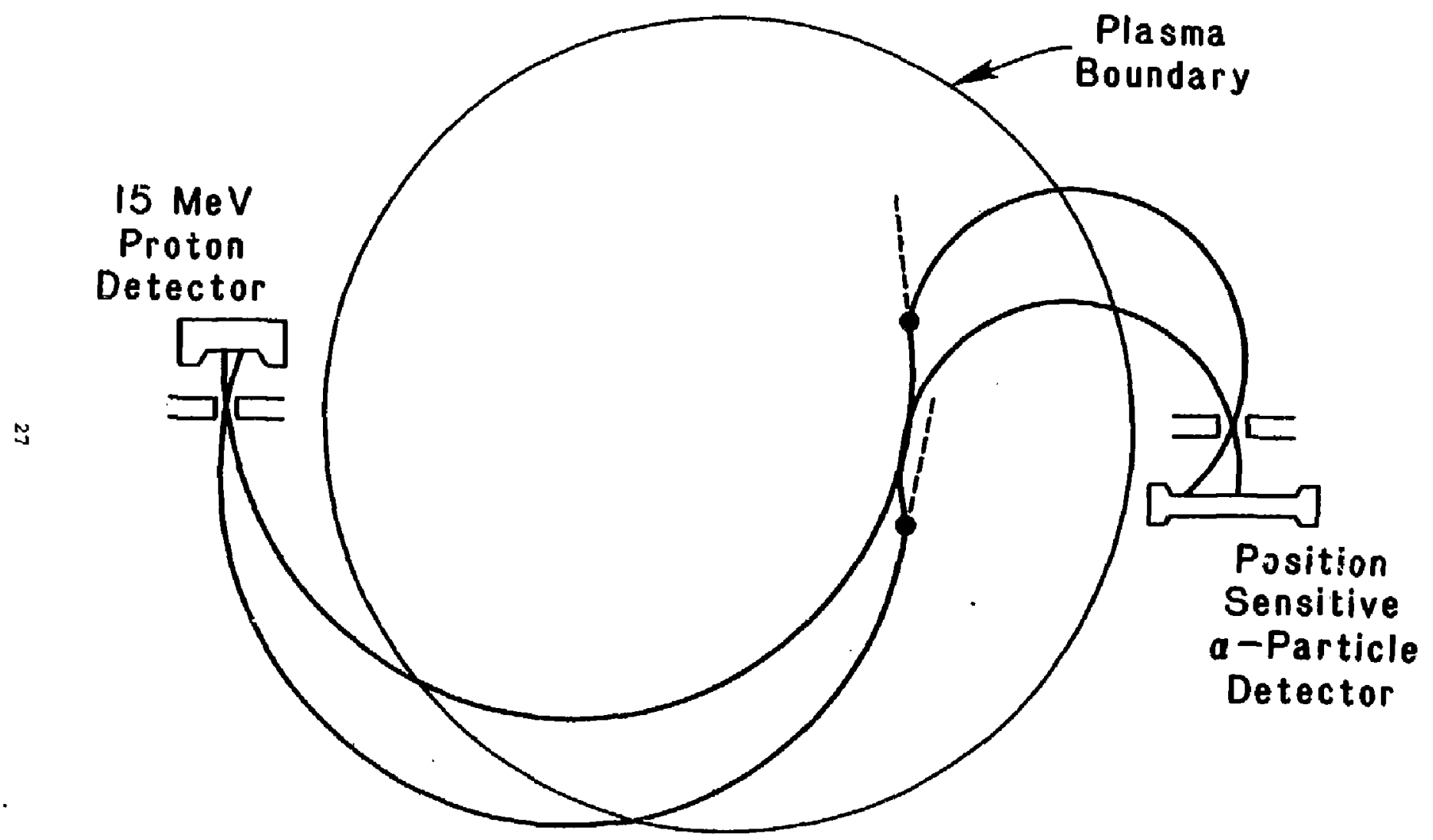

Fig. 6 
\#86x/266

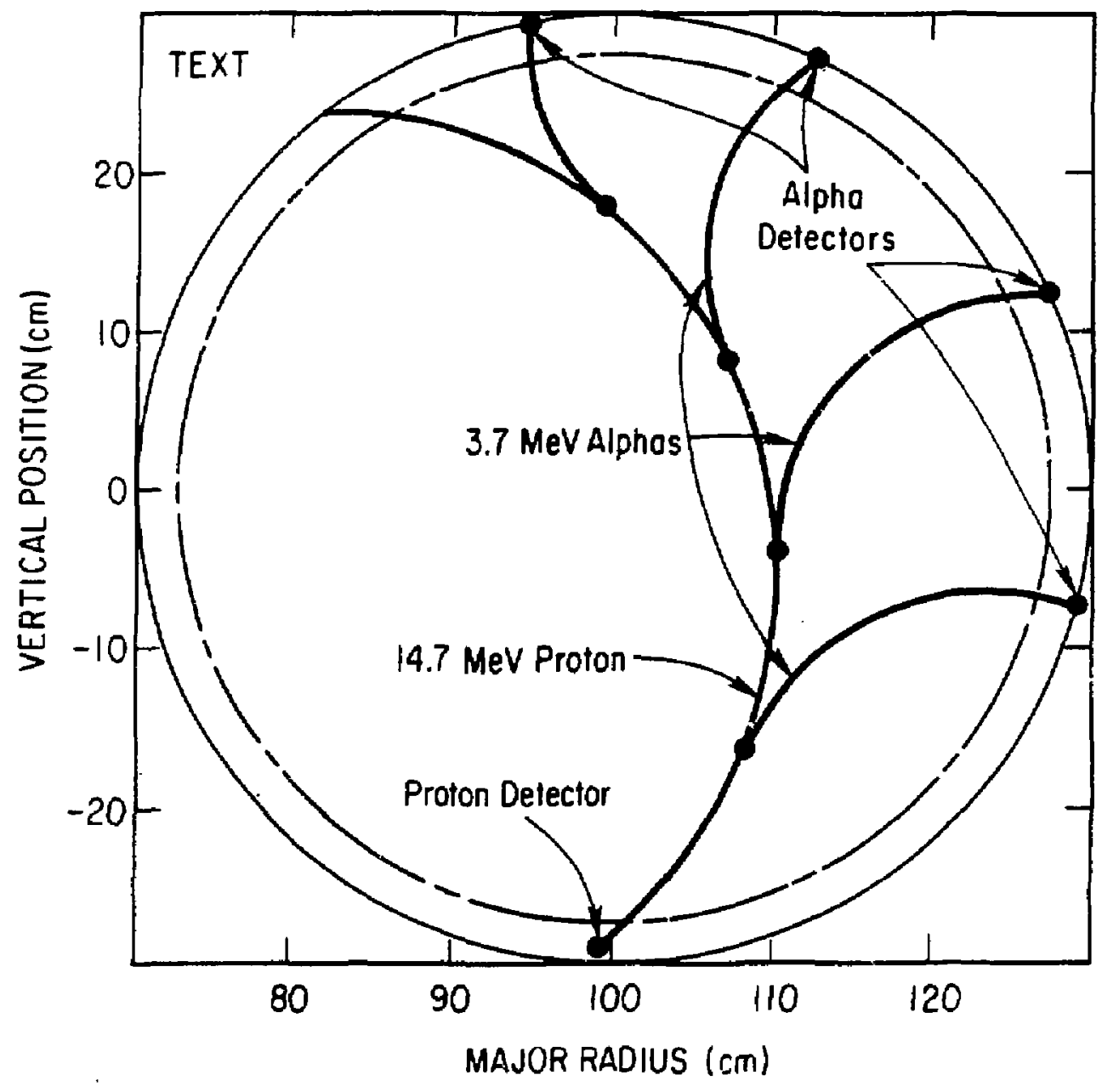

Fig. 7 
Dr. Frank J. Poolonl, Univ ot Wol langong, AUSTRALIA Prof. M.H. Brennan, Univ Sydney, NusTRALia

Plasmo Research Lob., Australian Nat. Univ., AUSTRALIA Prot. I.R. Jones, FIInders UnIV., NUSTRNLIA Prof. F. Ced, inst Thoo Phys, Austria

Prof. H. Helndier, institut fur Theortische Physlk, RUSTRIA M. Goossens, Astrongmisch Instltuut, BELGIUH Ecole Royale Mllitalre, Lab de Phys Plasmos, BELGiuM Com, of Europan, Dg Xil Fusion Prog, BELGIUM Prof. R, Bouclaue, Loborotoriu voor Natuurkunde, BELGlu. or. P.H. Sakanaka, Unlv Estadual, gaAzil InstItuto De Pasqulsas Espaclasi-INE, BARIL LIbrary, Atomle Enargy of Canado Lielted, CAHADA Or. M.P. BechynskI, MPB Tachnologles, InC., CNHADA Dr. H.H. Skarsgard, Univ of Saskatchewan, CANADA Dr. H. Barnard, Unirersity af Britlin Columble, CAHADA Prot. J. Telcharann, Uתlv. of Montreal, CANADA Prof. S.R. Sreanivasan, UnIversity of Calgary, CaNioh Prof. Tudor H. Johnston, lWRS-Enorgls, GANDA Dr. C,R. Jenes, UnIw, of Alberte, CANADA Dr. Peter Lukec, Komanskeho UnIv, CzECHDSLOVAKIA The Librarlan, Culhem Leboratory, ENGLAND Hrs. S.A. Hutchinson, JET LIbrary, ENGLAND C. Mouttet, Lab. de Physlaue des MIII eux Ionlsés, FRAMCE J. Reder, CEN/CNDARACHE - BOt 306, FRANCE Dr. Tom Mual, headmy Blbl lographle, HONG KOt's Preprint Library, Cenr Res inst Phys, HUNGARY Dr. B, Dasgupta, Sahe Ingt, IMJ|A Dr. R.K. Chhajlanl, VIkran Unlv. IMIA Dr. P. Ker, Institute for plasme Research, INoIA Dr. Phillip Rosenau, Isroal Inst Tech, ISRAEL Prof. S. Cupertan. Tel Avir University, ISRAEL LIbrarlan, Int'l Ctr Theo Phys, ITALY Prot. G. Rostogni, UnIv DI Padove, ITALY MIS5 CI\$IVE De Palo, Assoc EURATOHESUE, ITALY BJollatece, del CNR EURATON, ITAY

Dr. H. Yamato, Toanlbe Res Dor, JAPN

Prot. I. Kenakenl, Atomlc Energy Ror. Inetitute, JAPAN Prot. KyoJI NIshIkawo, UnIY of HIroshlme, JAPAN

Direc. Dept. Lg. Tokanak Ros, JAERI, JAPAN

Prat. Satosh1 Itah, Kyushu Univorsity. JAPW Research Into Center, Nagoya Unlvarsity, JAPAN Prof. S. Tenake, Kyato UnIversity, JAPAN Libraty, Kyoto univorsity, JAPA Prot. Nobuyukl Inoue, Uhlversity of Tokyo, JAPAY S. Hor I, JAERI, JAPAN MaH. KIm, Korea Adveneed Energy Research Insritute, KOREA Prot. D.l. Chol, hdy. Inst sel \& Tech, KOREA

Prot. B.S. LIley, Unlversity of Welkato, NEW ZENLNO Institute of Plasing Physles, PEOPLE's RePUBLIC OF CHINA LIbrarlan, Instltute of Phys., PEOPLE'S REPUBLIC OF CHINA LIbrary, Tsing Hua Universfty, PEOPLE'S REPUBLIC OF CHINA
Z. Li, Southwest inst. Physics, PEOPLE'S REPULIC OF CHINA Prof. J.A.C. Cabral, Inst Superlor Teen, PORTUGAL Dr. Oetavlan Petrus, AL I CUzA UnIrorslty, ROMANIA Dr. Johan de VIlliers, Plesme Physles, AEC, SO AFRICA Prot. H.A. Hellberg, University of Natol, SO AFRICA Fusion DIr. LIbrary, JEN, SPAIN

Dr. Lennart stentlo, Unlvarsity of UMEA, SWEDEN Library. Royol Inst Tech, SwEDEN

Prof. Hens wihelwson, Chalmers Unlv Tech, SWEDEN Centre Phys des PJasmas, Ecole Palytach Fad, SWITZERLAD Blbliotheak, Fon-Inst Voor plesne-Fysica, THE NETHERLANDS Dr. O.D. Ryutov, Slburlan Acad Scl, USSR Dr. G.A. EIItew, Kurchatow Instltute, USSR Dr. V.A. Glukhlkh, Inst EInctro-Physlcel, USSA Or. V.T. Tolok. Inst, Phys. Tech. USsR Dr. L,H, Kowrlzhnykh, I nstiturte Gen. Physles, USSR Prot. T.J.M. Eoyd, Unir Colloge $N$ Woles, WhLES Nuclear Res. Establishment, Julleh ttd., W. GERMANY atbllothek, Inst. Fur Plaseatorschung, W. GERMNY Dr. K. SchIhd Itr, Ruhr Univarsitat, W. GERMANr ASOEX Regding Ran, IPP/Max-Plenck-I astl tut fü

Plasmaphy: $1 k$, w. GERUAYY LIbrarlan, Hex-Planck InstItut, W. GERMWY Prof. R.K. Janov, Inat Phys, YUCOSLAYIA 